\title{
Macroscopy and Microscopy Urinalysis: \\ A Vital Screening Procedure for Urinary Tract Infections (UTIs) in a Hospital in Awka, Nigeria
}

\author{
Uchechukwu G. Nwankwo (Corresponding author) \\ Department of Microbiology, College of Natural and Applied Sciences, Renaissance \\ University Ugbawka, Enugu State, Nigeria. E-mail: u.nwankwo2016@gmail.com
}

\section{Chinenye U. Ezebialu}

Department of Applied Microbiology and Brewing, Faculty of Biosciences, Nnamdi Azikiwe University Awka, Anambra State, Nigeria

Joachim O. Ezeadila

Department of Applied Microbiology and Brewing, Faculty of Biosciences, Nnamdi Azikiwe University Awka, Anambra State, Nigeria

\section{Ikechukwu Okoli}

Department of Applied Microbiology and Brewing, Faculty of Biosciences, Nnamdi Azikiwe University Awka, Anambra State, Nigeria

Received: Dec. 23, 2019 Accepted: Jan. 19, 2020

doi:10.5296/jbls.v11i1.16454 URL: https://doi.org/10.5296/jbls.v11i1.16454

\begin{abstract}
Urine examination has been employed in clinical practice as the most common screening laboratory method for early detection of urinary tract infections (UTIs) or renal disorder. This study was undertaken to ascertain the usefulness of urine macroscopy and microscopy as vital screening procedure for diagnosing UTI among antenatal patients in a teaching hospital in Awka, Nigeria. Freshly voided midstream urine specimens of 269 pregnant women were collected and examined using macroscopic, microscopic and culture methods. The sensitivity, specificity, positive predictive value and negative predictive value of urine colour, and
\end{abstract}


microscopic features were compared with urine culture in diagnosis of UTI. Statistical analysis was done using SPSS and Epi info ${ }^{\circledR}$ and P-value was set at $<0.05$ significant level. One hundred and seven specimens showed positive urine cultures. Out of these 107 specimens, $60(56.1 \%)$ also had deviation from normal urine colour and 77(72\%) were positive on urine microscopy. Macroscopic examination showed that a significant relationship exists between urine colour and positive urine culture $(\mathrm{p}=0.0001)$. The sensitivity and specificity of urine colour with respect to UTI were $56.7 \%$ and $67.9 \%$ respectively. Urine microscopy revealed that the positive features had a significant relationship with positive urine culture $(\mathrm{p}=0.000)$. Pyuria alone showed the specificity and positive predictive value of $100 \%$ each. The sensitivity, specificity, positive predictive value and the negative predictive value of combination of positive microscopic features were $72 \%, 64.8 \%, 57.5 \%$ and $77.8 \%$ respectively. Examination of colours and microscopic features of urine are therefore vital in predicting urinary tract infection.

Keywords: renal disorder, microscopic features, urine culture, antenatal, pyuria, midstream urine

\section{Introduction}

Urinary tract infection (UTI) can be caused by the presence and growth of microorganisms in the urinary tract (Fazeela et al., 2015). Anatomically, UTI can be classified into lower urinary tract infection involving the bladder and urethra and upper urinary tract infection involving the kidney, pelvis, and ureter (Parveen et al., 2011). Urinary tract infections could be acquired from hospitals (nosocomial infections), among patients admitted in hospitals and also from community settings (Willey et al., 2008; Boye et al., 2012). UTI accounts for 35\% nosocomial infection and is the second cause of bacteraemia in hospitalized patients (Alemu et al., 2012). Community acquired urinary tract infection (CA-UTI); could therefore be defined as an infection of the urinary tract that occurs in the community or within less than 48 hours of hospital admission and was not incubating at the time of hospital admission (Kabugo et al., 2016).

Urinary Tract Infection is one of the common bacterial infections that complicates pregnancy (Onoh et al., 2013) hence the reason for choice of pregnant women as the study group in this research. In pregnancy, UTI may be symptomatic, commonly manifested as urethritis, cystitis (inflammation of the bladder) or pyelonephritis (kidney inflammation); or it may remain asymptomatic (Parveen et al., 2011; Boye et al., 2012). Untreated asymptomatic bacteriuria is however a risk factor for acute cystitis (40\%) and pyelonephritis (25-30\%) in pregnancy (Alfred et al., 2013). Pregnancy enhances the progression from asymptomatic to symptomatic bacteriuria which could lead to other adverse obstetric outcomes such as prematurity, low-birth weight and higher fetal mortality rates (Getachew et al., 2012). In Nigeria, the prevalence of UTI among antenatal patients has been reported in Benin, Ebonyi and Nassarawa State as 13.8\%, 55\% and 62.67\% respectively (Alfred et al., 2013; Onuoha and Fatokun, 2014; Ajide et al., 2016).

The examination of urine (urinalysis) has been used as one of the most common screening methods to diagnose any disorder of the urinary tract. For urine to be adequately examined, the 
macroscopic and microscopic examination as well as culture must be conducted on such urine specimen (Charlotte et al., 2019; Mina et al., 2017; Alfred et al., 2013). Some researchers were of the view that any number of organisms in urine that is equal to or greater than $10^{5} \mathrm{cfu} / \mathrm{ml}$ can result to UTI (Ahmed et al., 2016; Olga et al., 2015; Getachew et al., 2012).

Normal freshly-voided urine is pale yellow to deep amber in color (Boye et al., 2012). Cloudy urine may indicate an infection of the urinary tract (Foot and Fraser, 2006). Pale yellow and clear urine is usually associated with increased production of dilute urine whereas deep yellow concentrated urine occurs as a result of dehydration with free water conservation (Foot and Fraser, 2006). Foot and Fraser (2006) also reported that large volumes of dilute urine can be produced as a result of conditions like diabetes insipidus and pale urine can also be seen after catheters are flushed and sterile water drains into the catheter collecting chamber. Turbidity or cloudiness may be caused by excessive red blood cell, cellular materials or protein in the urine (Fazeela et al., 2015). Red/blood stained urine commonly result from renal calculi, urinary tract infection, and malignancy (Yun et al., 2004; Cheesbrough, 2006). In some cases fresh blood may arise from perineal sources (for example, haemorrhoids, menstrual blood) and this should be distinguished from renal causes (Foot and Fraser, 2006). Hence, macroscopic haematuria should always be investigated (Yun et al., 2004).

The urine culture is a gold standard diagnostic test for asymptomatic bacteriuria (Mina et al., 2017; Alfred et al., 2013), but it is expensive and time-consuming; the result may only be ready after about 48 hours. Some inexpensive screening methods (involving dipstick test and microscopy) are useful in fast detection of people who are at high risk of UTI (Kabugo et al., 2016; Agbagwa and Ifeanacho, 2015). Several research findings at Ghana (Donkor et al., 2019), Cameroun (Charlotte et al., 2019), Iran (Mina et al., 2017), Kenya (Nabbugodi et al., 2015) and Benin (Alfred et al., 2013) have reported on the use of routine macroscopy and microscopy to screen for UTI in pregnancy. It is vital to ensure that pregnant women attain the highest level of health because this goes a long way to determine the outcome of pregnancy (Alfred et al., 2013). There is paucity of data on using simple urinalysis as a screening method for UTI among pregnant women in Awka. Studies done at some cities in Nigeria like Port Harcourt, Abuja and Benin adopted the dipstick test and microscopy to screen for UTI (Agbagwa and Ifeanacho, 2015; Amaeze et al., 2013; Alfred et al., 2013). None of these studies established any relationship between urine colour and positive urine culture. This study therefore intends to address the usefulness of urine colour and microscopy as vital rapid screening tests that may be used to predict UTI.

\section{Materials and Methods}

\subsection{Study Site and Specimen Collection}

This study was conducted on antenatal patients at Chukwuemeka Odumegwu Ojukwu University Teaching Hospital in Awka, Nigeria. Awka is the capital city of Anambra State in south eastern Nigeria. Awka lies on the longitude $7^{\circ} \cdot 4^{\prime} 20.1972^{\prime \prime} \mathrm{E}$ and latitude $612^{\prime} 37.9008^{\prime} \mathrm{N}$. Besides being one of the five biggest predominantly Igbo cities in Nigeria, the city is an important trade and educational center. It houses one of the largest and foremost hospitals (now teaching hospital) in the state - Chukwuemeka Odumegwu Ojukwu University Teaching 
Hospital. It is serving as a referral center for Hospitals in Anambra State and beyond. There are various specialist units in the hospital including Obstetrics and Gynaecology, Internal Medicine, Paediatrics, Surgery and Pathology.

The study with a reference number (COOUTH/AA/VOI.1.010) was approved by the ethical committee of the hospital. The study was carried out over a period of nine months from $11^{\text {th }}$ of March to $31^{\text {st }}$ December, 2016. A total of 269 pregnant women were randomly selected for the study. These were outpatients attending antenatal clinic. They included those women who have not taken antibiotics within 2 weeks before presentation at the clinic and were willing to participate in the study. Clean catch midstream (morning) urine specimens were used for the study. Sterile leak-proof specimen bottles (which have been previously labeled) were distributed to the women after they were instructed on how to collect such specimen (which involves the initial cleaning of the urethral area with clean water) and the importance of clean catch midstream urine in the study. The specimens were transported to the laboratory in specimen box containing ice pack (Kabugo et al., 2016; Emiru et al., 2013) and analyzed within 1-2 hours of collection (Cheesbrough, 2006; Onoh et al., 2013; Kabugo et al., 2016).

\subsection{Laboratory Analysis of Urine Specimens}

\subsubsection{Macroscopic Analysis}

The part of macroscopic urinalysis employed in this study was visual observation for turbidity. The urine specimens were examined and the results of macroscopic properties recorded in terms of colour, clearity and cloudiness as has been described (Charlotte et al., 2019; Kabugo et al., 2016; Fazeela et al., 2015; Amaeze et al., 2013). Urine specimens whose colours showed amber, pale and deep yellow but clear were regarded as normal, while specimens that showed amber to deep yellow but cloudy, colourless and red/blood stained were regarded as abnormal (Fazeela et al., 2015; Amaeze et al., 2013; Boye et al., 2012).

\subsubsection{Microscopy}

Urine microscopy was carried out by using wet preparation to detect presence of pus cells (i.e white blood cells), red cells, casts, parasites, yeast cells, crystals, bacterial cells (since the urine were freshly collected). The preparation and examination of wet preparation was done using the guidelines given by Cheesbrough (2006) as follows:

Approximately $10 \mathrm{ml}$ of well mixed urine was aseptically transferred to labeled conical tubes. The tubes were centrifuged at 1000 revolutions per minute (rpm). The supernatant fluid was transferred into another container. The sediment was re-mixed by tapping the bottom of the tube. One drop of the well mixed sediment was transferred to a clean slide and covered with a cover slip. The preparation was examined microscopically using the X10 and X40 objective lenses. Reports were given based on the specification given by Cheesbrough (2006), Alfred et al., (2013), Ince et al., (2016) as follows:

Pyuria is the presence of $\geq 10$ pus cells or white blood cells per high power field (hpf) of urine sample, $>1$ bacteria, presence of fungi, parasites, presence of significant crystals (eg cystine) or a large number of crystals. 


\subsubsection{Urine Culture}

The urine was cultured using a calibrated wire loop technique as described by Cheesbrough (2006). The loop used transfers an inoculum of $0.002 \mathrm{ml}$. The calibrated loop was used aseptically to transfer specimens on Cystein Lactose Electrolyte Deficient (Rapid Labs) media and incubated aerobically at $37^{\circ} \mathrm{C}$ for $18-24$ hours (Cheesbrough, 2006; Donkor et al., 2019). Following incubation, significant bacterial growth was taken as any count of uniform colonies equal to or in excess of $10^{4} \mathrm{CFU}$ per milliliter of urine (Alao and Akintunde, 2012; Emiru et al., 2013; Akter et al., 2014; Mina et al., 2017). The colony count/bacterial numbers were estimated using a simple Mathematical method (Cheesbrough, 2006).

\subsection{Statistical Analysis}

Data were coded, entered and analyzed using Statistical Package for Social Science (SPSS), version 22, EPI Info ${ }^{\circledR}$ version 7.2.1.0. Study findings were explained in words and tables. Results/ proportions for categorical variables were compared using percentages, $2 \times 2$ tables and chi square test. In all cases, P-value less than 0.05 was taken as statistically significant. The sensitivity, specificity, positive predictive value and negative predictive value were calculated as described by Nabbugodi et al. (2015): Sensitivity = A/A+B X 100, Specificity = $\mathrm{C} / \mathrm{C}+\mathrm{D}$ X 100, Positive predictive value $=\mathrm{A} / \mathrm{A}+\mathrm{D} \mathrm{X} 100$ and Negative predictive value $=$ $\mathrm{C} / \mathrm{C}+\mathrm{B} \mathrm{X} 100$. Where $\mathrm{A}=$ total number of positive urine microscopy that are UTI positive, $\mathrm{B}$ =number of positive microscopy that are negative for UTI, $\mathrm{C}=$ total number of negative microscopy that are UTI negative and $\mathrm{D}=$ number of negative microscopy that are UTI positive.

\section{Results}

Out of the 269 antenatal patients examined, 107 (38.7\%) had positive urine cultures. Out of 107 women who had positive urine cultures, 60(56.1\%) also had deviation from normal urine colour and $77(72 \%)$ were positive on urine microscopy. The urine colours observed in this study ranged from pale yellow, deep yellow, amber, colourless to red (Table 1). The higher percentage $157(58.4 \%)$ of urine samples were within the normal urine colours, while $112(41.6 \%)$ had deviation from normal urine colours of all the specimens. A higher percentage of women whose urine colour deviated from normal had positive urine cultures and this was statistically significant $(\mathrm{p}=0.0001)$ (Table 2). 
Table 1. Macroscopic characteristics of urine specimens

\begin{tabular}{llccc}
\hline Variable/ & \multirow{2}{*}{ Categories } & Frequency $(\%)$ & \multicolumn{2}{c}{ Urine culture } \\
\cline { 5 - 5 } Appearance & & & Negative (\%) Positive (\%) \\
\hline \multirow{3}{*}{ Amber } & Amber, clear & $131(48.7)$ & $87(64.4)$ & $44(33.6)$ \\
& Amber, slightly cloudy & $14(5.2)$ & $7(50)$ & $7(50)$ \\
& Amber, cloudy & $68(25.3)$ & $29(42.6)$ & $39(57.4)$ \\
\hline \multirow{3}{*}{ Pale yellow } & Pale yellow, clear & $19(7.1)$ & $16(84.2)$ & $3(15.8)$ \\
& Pale yellow, slightly cloudy & $1(0.4)$ & 0 & $1(100)$ \\
& Pale yellow, cloudy & $11(4.1)$ & $2(18.2)$ & $9(81.8)$ \\
\hline \multirow{2}{*}{ Deep yellow } & Deep yellow, clear & $7(2.6)$ & $4(57)$ & $3(43)$ \\
& Deep yellow, slightly cloudy & $2(0.7)$ & $1(50)$ & $1(50)$ \\
\hline Colourless & Deep yellow, cloudy & $4(1.5)$ & $2(50)$ & $2(50)$ \\
\hline Red & Colourless, clear & $11(4.1)$ & $6(55)$ & $5(45)$ \\
\hline
\end{tabular}

Table 2. Sensitivity, specificity, and predictive values of urine colour tests in diagnosing UTI

\begin{tabular}{lcccc}
\hline \multirow{2}{*}{ Urine Colour } & \multicolumn{2}{c}{ Prevalence of UTI (\%) } & \multirow{2}{*}{ Total } & \multirow{2}{*}{ P-value } \\
\cline { 2 - 3 } & Positive & Negative & & \\
\hline Normal & $47(29.9)$ & $110(70.1)$ & $157(58.4)$ & \multirow{2}{*}{ De.0001 } \\
Deviation & $60(53.6)$ & $52(43.4)$ & $112(41.6)$ & \\
\hline Total & $107(39.8)$ & $162(60.2)$ & $269(100.0 \%)$ & \\
\hline
\end{tabular}

Microscopic examination of urine samples revealed that 7(2.6\%) had significant pyuria out of the 269 samples examined, though 4 out of the 7 specimens occurred in combination with other features. The sensitivity and specificity of pyuria in our study were $6.1 \%$ and $100 \%$ respectively while the positive predictive value and negative predictive value were $100 \%$ and $50 \%$ respectively. Statistically, there was a significant relationship between pyuria and positive urine cultures.

The percentage of other features observed microscopically (which occurred singly and not in combination) include epithelial cells, bacteria cells, crystals, yeast cells, pus cells and crenated red cells (Table 3). The crystals observed include calcium oxalate (31:91.2\%), triple phosphate (1:2.9\%) and cysteine crystals (2:5.9\%).

Out of the 269 specimens tested, 43(15.9\%) showed more than one positive microscopic features, and out of these 43 specimens, $28(65.1 \%)$ were positive for UTI while $15(34.9 \%)$ where negative for UTI. Among 135(50.2\%) urine specimens which did not show any microscopic feature, a higher percentage 105(77.8\%) was observed among the women without positive urine cultures compared to those with UTI 30(22.2\%). The relationship between positive microscopic features and prevalence of UTI observed in this study is statistically significant ( $\mathrm{p}=0.000$, Table 3 ). The sensitivity, specificity, positive predictive value and the negative predictive value of combination of positive microscopic features were $72 \%, 64.8 \%, 57.5 \%$ and $77.8 \%$ respectively (Table 4 ). 
Table 3. Microscopic examination of urine specimens with respect to UTI

\begin{tabular}{lcccc}
\hline \multirow{2}{*}{ Microscopic features } & \multicolumn{2}{c}{ Urine culture (\%) } & \multirow{2}{*}{ Total } & \multirow{2}{*}{ P-value } \\
\cline { 2 - 3 } & Positive & Negative & & \\
\hline Epithelial cells & $25(47.2)$ & $28(52.8)$ & $53(19.7)$ & \\
Bacterial cells & $14(87.5)$ & $2(12.5)$ & $16(5.9)$ \\
Crystals & $3(23.1)$ & $10(76.9)$ & $13(4.8)$ & \\
Yeast cells & $4(80.0)$ & $1(20.0)$ & $5(1.9)$ \\
Pus cells & $3(100.0)$ & $0(0.0)$ & $3(1.1)$ \\
Crenated red cells & $0(0.0)$ & $1(100.0)$ & $1(0.4)$ \\
None & $30(22.2)$ & $105(77.8)$ & $135(50.2)$ & \\
$>$ 1 Microscopic/Combination of & $28(65.1)$ & $15(34.9)$ & $43(15.9)$ & $\mathbf{0 . 0 0 0}$ \\
features & & & & \\
\hline Total & $107(39.8)$ & $162(60.2)$ & $269(100.0)$ & \\
\hline
\end{tabular}

NOTE: the frequencies captured in the table represent the number of specimens that tested positive for each/combination of feature(s).

Table 4: Sensitivity, specificity and predictive values of urine microscopy test in diagnosing UTI in antenatal women

\begin{tabular}{lccc}
\hline \multirow{2}{*}{ Urine microscopy } & \multicolumn{2}{c}{ Urine culture $(\%)$} & \multirow{2}{*}{ Total } \\
\cline { 2 - 3 } & Positive & Negative & \\
\hline Positive & $77(72)$ & $30(28)$ & $107(39.8)$ \\
Negative & $57(35.2)$ & $105(64.8)$ & $162(60.2)$ \\
\hline Total & $107(39.8)$ & $162(60.2)$ & $269(100.0 \%)$ \\
\hline
\end{tabular}

Keys: Sensitivity $=77 / 77+30 \times 100=72 \%$

Specificity $=105 / 105+57 \times 100=64.8 \%$

Positive predictive value $=77 / 77+57 \times 100=57.5 \%$

Negative predictive value $=105 / 105+30 \times 100=77.8 \%$

\section{Discussion}

Macroscopic analysis of urine samples conducted in this study showed urine colours that ranged from pale yellow, amber to red which is in line with the findings of some other researchers (Agbagwa and Ifeanacho, 2015; Kabugo et al., 2016). The normal urine color, ranges from pale yellow to deep amber and this is as a result of the pigment called urochrome as stated by Boye et al. (2012) and Foot and Fraser (2006). However, deviation from the normal color extremes (pale yellow - deep amber) could be as a result of disease conditions (Cheesbrough, 2006) or as result of excessive red blood cell, cellular materials or protein in the urine (Fazeela et al., 2015). These deviations however, are observed in this study as normal urine colours that are cloudy, colourless and red with percentage of $112(41.6 \%)$ and this is consistent with the findings of Boye et al. (2012) and Amaeze et al. (2013). Higher prevalence of positive cultures was observed among the women with deviation from normal urine colours 
$60(53.6 \%)$, while $52(46.4 \%)$ women from the same group were negative for UTI and this difference was statistically significant $(\mathrm{P}=0.0001)$. This finding is in accordance with Cheesbrough (2006) and that deviation from normal urine colours could be an indicator for an existing infection or diseased condition. Urine colour appeared statistically significant in this research as an indicator suggesting an existing disease condition but the specificity is not up to $100 \%$. The specificity is $67.9 \%$ and this means $32.1 \%$ of the women will need confirmatory testing with urine culture. Also a negative predictive value of $70.1 \%$ was obtained for urine colour in this study. This value is high and means that such percentage of women with negative test result will probably not have UTI and this gives credibility to the use of deviation from normal urine colour as an indicator of an existing disease condition. Majority of the women in this study had deviation from normal urine colours probably because of other pigments excreted in their urine (Foot and Fraser, 2006) like glucose and amino acid (Boye et al., 2012). These pigments were not detected in this study as we did not carry out dip stick urinalysis. A milky appearance (which is a deviation from characteristic colour of urine) may also arise with lipiduria, chyluria, and urinary tract infection with neutrophilia (Foot and Fraser, 2006).

In our study, Pyuria alone showed specificity of $100 \%$ while the positive predictive value and negative predictive value were $100 \%$ and $50 \%$ respectively. The specificity and positive predictive value of pyuria suggest that none of the women with negative urine culture will need confirmatory testing with urine culture. A study carried out at Iran reported lower values (64\% and $16 \%$ ) for specificity and positive predictive values respectively for pyuria while the sensitivity and negative predictive values were $100 \%$ each for pyuria (Mina et al., 2017). Pyuria and positive urine cultures have a significant relationship, and with the $100 \%$ specificity obtained in this study, it can be considered for use in rapid diagnosis of UTI. Lentz (2009) has a similar view and stated that microscopic urinalysis is the most accurate means of detecting pyuria, and the most valuable rapid test in diagnosis of UTI. There is however, need for caution and setting of standard in the use of pyuria as a rapid diagnostic method in detecting UTI. This is because the use of $\geq 10$ pus cells for a positive pyuria showed higher specificity (100\%) and positive predictive value as shown in this work but use of $\geq 5$ pus cells showed lower specificity and positive predictive value as obtained in other works (Mina et al., 2017, Alfred et al., 2013)

A greater percentage (77.8\%) of the women without any of the microscopic features, had no significant growth in their urine cultures compared to only $28 \%$ of no significant growth in those with microscopic features. From this, it could be inferred that presence of significant numbers of microscopic features in urine is an indicator for UTI as has been reported (Cheesbrough, 2006; Alfred et al., 2013; Mina et al., 2017). There is however, a significant relationship between the microscopic features observed in this study and the prevalence of UTI. The combination of these microscopic features also showed high prevalence of UTI in this study which also strengthens the above report on the presence of significant number of microscopic features as an indicator of UTI.

The high sensitivity and specificity of urine microscopy obtained in this study is comparable to studies done at Kenya that reported sensitivity and specificity of $67.5 \%$ and $88.2 \%$ respectively (Nabbugodi et al., 2015). A higher sensitivity of $90.9 \%$ was also obtained in Benin City, Nigeria (Alfred et al., 2013). A high negative predictive value for microscopy 
$(77.8 \%)$ obtained in this study, implies that such percentage of patients with negative test results are very unlikely to have UTI. The value is however lower than that obtained at Benin (Alfred et al., 2013) and Iran (Mina et al., 2017).

The overall prevalence of UTI in this study is high and of great concern. Pregnancy is one the factors that predispose to UTI due to ureteral dilation, urinary stasis (abnormalities in the structure of urinary outflow tract that may result in incomplete emptying of the bladder), reduced immune function, and presence of vesicoureteric reflex (backward flow of urine from bladder into the kidney) and difficulty with hygiene due to a distended pregnant belly (Onoh et al., 2013; Ajide et al., 2016). It has also been reported that up to 70\% of pregnant women develop glycosuria, which encourages bacteria growth in urine (Alemu et al., 2012; Getachew et al., 2012).

\section{Conclusion and Recommendation}

There is a significant relationship between urine colour, urine microscopy, and positive urine cultures in urinary tract infection (UTI). Urine colour and urine microscopy (particularly pyuria) tests had high sensitivity and specificity in screening for UTI. Such urinalysis methods which are inexpensive and less time consuming should be employed as a routine screening procedure for UTI in developing countries. The usefulness of macroscopic and microscopic examination of urine cannot be overemphasized in predicting UTI, more so in developing countries like Nigeria where financial constraint has made it practically impossible to use urine culture as a routine screening among pregnant women.

There is need for a particular standard to be adopted for significant pyuria as a screening method for UTI.

\section{References}

Agbagwa, O. E., \& Ifeanacho, E. J. U. (2015). The Prevalence of UTI Pathogens in Urine Specimen Obtained from a Hospital in Rivers State Nigeria. Journal of Microbiology Research, 5(5), 143-148. https://doi.org/10.5923/j.microbiology.20150505.01

Ahmed, M. A., Shukla, G. S., \& Bajaj, H. K. (2016). Incidence of Urinary Tract Infections and determination of their susceptibility to antibiotics among pregnant women. International Journal of Cell Science and Biotechnology, 5, 12-16.

Ajide, B., Adogo, L., Saidu, H., \& Enna, M. (2016). Prevalence of urinary tract infection among pregnant women receiving antenatal care in two primary Health Care Centres in Karu Nasarawa State, Nigeria. British Microbiology Research Journal, 12(3), 1-8. https://doi.org/10.9734/BMRJ/2016/23191

Akter, L., Haque, R., \& Salam, A. (2014). Comparative evaluation of chromogenic agar medium and conventional culture system for isolation and presumptive identification of uropathogens. Pakistan Journal of Medical Science, 30(5), 1033-1038. https://doi.org/10.12669/pjms.305.5243

Alao, F. O., \& Akintunde, F. A. (2012). Asymptomatic bacteriuria among students of Bellstech, Ota, Nigeria. The Pacific Journal of Science and Technology, 13(2), 342-347. 
Alemu, A., Moges, F., Shiferaw, Y., Tafess, K., Kassu, A., Anagaw, B., \& Agegn, A. (2012). Bacterial profile and drug susceptibility pattern of urinary tract infection in pregnant women at university of Gondar Teaching Hospital, Northwest Ethiopia. Biomed Central Research Notes; 5: 197:1-7. https://doi.org/10.1186/1756-0500-5-197

Alfred, A. O., Chiedozie, I., \& Martin, D. U. (2013). Pattern of asymptomatic bacteriuria among pregnant women attending an antenatal clinic at a private health facility in Benin, South-South Nigeria. Annals African Medicine, 12, 160-164. https://doi.org/10.4103/1596-3519.117625

Amaeze, N. J., Abah, A. U., \& Okoliegbe, I. N. (2013). Prevalence and antibiotic susceptibility of uropathogens among patients attending University of Abuja Teaching Hospital, Gwagwalada, Abuja. International Journal of Medicine and Medical Sciences, 5(10), 460-466. https://doi.org/10.5897/IJMMS28

Boye, A., Siakwa, P. M., Boampong, J. N., Koffuor, G. A., Ephraim, R. K. D., Amoateng, P., Obodai, G., \& Penu, D. (2012). Asymptomatic urinary tract infections in pregnant women attending antenatal clinic in Cape Coast, Ghana. E3 Journal of Medical Research, 1(6), 074-083.

Charlotte, T. N., Cecile, O. E., Chrystelle, N. C., Cedric, E. E., Théophile, N. N., \& Emile, M. (2019). Clinical presentation, risk factors and pathogens involved in bacteriuria of pregnant women attending antenatal clinic of 3 hospitals in a developing country: a cross sectional analytic study. BMC Pregnancy and Childbirth, 19(143), 6 pages. https://doi.org/10.1186/s12884-019-2290-y

Cheesbrough, M. (2006). District Laboratory Practice in Tropical Countries. (Part 2). Cambridge University Press: London. p. 105-115. https://doi.org/10.1017/CBO9780511543470

Donkor, E. S., Horlortu, P. Z., Dayie, N. T., Obeng-Nkrumah, N., \& Labi, A. (2019). Community acquired urinary tract infections among adults in Accra, Ghana. Infection and Drug Resistance, 12, 2059-2067. https://doi.org/10.2147/IDR.S204880

Emiru, T., Beyene, G., Tsegaye, W., \& Melaku, S. (2013). Associated risk factors of urinary tract infection among pregnant women at Felege Hiwot Referral Hospital, Bahir Dar, North West Ethiopia. BMC Research Notes, 6(292), 1-6. https://doi.org/10.1186/1756-0500-6-292

Fazeela, M., Nelofer, J., Musarat, R., Zubia, M., Sabeena, R., Ayesha, M., Rahat, N. (2015). Prevalence of symptomatic and asymptomatic urinary tract infection in humans. World Journal of Zoology, 10(4), 310-312. https://doi.org/10.5829/idosi.wjz.2015.10.4.95300

Foot, C. L., \& Fraser, J. F. (2006). Uroscopic rainbow: modern matula medicine. Postgraduate Medical Journal, 82, 126-129. https://doi.org/10.1136/pgmj.2005.037598

Getachew, F., Gizachew, Y., Yitayih, W., \& Zufans, S. (2012). The Prevalence and Antimicrobial Susceptibility Pattern of Bacterial Uropathogens Isolated from Pregnant women. European Journal of Experimental Biology, 2(5), 1497-1502.

İnce, F. D., Ellidağ, H. Y., Koseoğlu, M., Şimşek, N., Yalçın, H., \& Zengin, M. O. (2016). The comparison of automated urine analyzers with manual microscopic examination 
for urinalysis automated urine analyzers and manual urinalysis. Practical Laboratory Medicine, 5, 14-20. https://doi.org/10.1016/j.plabm.2016.03.002

Kabugo, D., Kizito, S., Ashok, D. D., Graham, A. K., Nabimba, R., Namunana, S., Najjuka, F. C. (2016). Factors associated with community-acquired urinary tract infections among adults attending assessment centre, Mulago Hospital Uganda. African Health Science, 16(4), 1131-1142. https://doi.org/10.4314/ahs.v16i4.31

Lentz, G. M. (2009). Urinary Tract Infections in Obstetrics and Gynecology. Global Library of Women's Medicine; (ISSN: 1756-2228). https://doi.org/10.3843/GLOWM.10118

Mina, E., Sima, T., \& Roksana, D. (2017). Asymptomatic bacteriuria in pregnant women attending Boo-Ali Hospital Tehran Iran: Urine analysis vs. urine culture. Electronic Physician, 9(11), 5760-5763. https://doi.org/10.19082/5760

Nabbugodi, W. F., Gichuhi, W. J., \& Mugo, N. W. (2015). Prevalence of urinary tract infection, microbial aetiology, and antibiotic sensitivity pattern among antenatal women presenting with lower abdominal pains at Kenyatta National Hospital, Nairobi, Kenya. The Open Access Journal of Science and Technology, 3, 1-6. https://doi.org/10.11131/2015/101115

Olga, I. C., Bilchenko, A., \& Igor, K. (2015). Extended Spectrum Beta-Lactamase Production in Uropathogens Isolated from Hospitalized Patients with Chronic Pyelonephritis. The Open Urology \& Nephrology Journal, 8, 71-75. https://doi.org/10.2174/1874303X01508010071

Onoh, R. C., Umeora, O. U. J., Egwuatu, V. E., Ezeonu, P. O., \& Onoh, T. J. P. (2013). Antibiotic Sensivitity pattern of Uropathgens from Pregnant Women with Urinary Tract, Infection in Abakaliki, Nigeria. Infection and drug Resistance, 6, 225-233. https://doi.org/10.2147/IDR.S46002

Onuoha, S. C., \& Fatokun, K. (2014). Prevalence and antimicrobial susceptibility pattern of Urinary Tract Infection (UTI) among pregnant women in Afikpo, Ebonyi State, Nigeria. American Journal of Life Sciences; 2(2), 46-52. https://doi.org/10.11648/j.ajls.20140202.12

Parveen, K., Momen, A., Begum, A. A., \& Begum, M. (2011). Prevalence of Urinary Tract Infection during Pregnancy. J. Dhaka National Med. Coll. Hos., 17(02), 8-12. https://doi.org/10.3329/jdnmch.v17i2.12200

Willey, J. M., Sherwood, M., \& Woolverton, C. J. (2008). Nosocomial infections. Prescott, Harley and Kleins Microbiology, $7^{\text {th }}$ ed. New York:Mc Graw Hill. 900, 908-909.

Yun, E. J., Meng, M. V., \& Carroll, P. R. (2004). Evaluation of the patient with hematuria. Medical Clinics of North America, 88(2), 329-343. https://doi.org/10.1016/S0025-7125(03)00172-X

\section{Copyright Disclaimer}

Copyright for this article is retained by the author(s), with first publication rights granted to the journal.

This is an open-access article distributed under the terms and conditions of the Creative Commons Attribution license (http://creativecommons.org/licenses/by/4.0/). 